\title{
Library Management System using RFID
}

\author{
S. Thiruvengadam \\ Under Graduate Student \\ Dept. of Computer Science and Engineering \\ SCSVMV (Deemed to be University), Enathur, \\ Kanchipuram 631 502, Tamil Nadu, India
}

\author{
S. Gokulakrishnan \\ Assistant Professor \& Placement Coordinator \\ Dept. of Computer Science and Engineering \\ SCSVMV (Deemed to be University), Enathur \\ Kanchipuram 631 502, Tamil Nadu, India
}

\begin{abstract}
This paper will discuss about the usage of RFID or Radio Frequency Identification in libraries. This will highlight the advantages of using RFID in Library management and discuss the various purposes of deploying such technology to use. The RFID technology is a form of wireless identification technology that uses radio waves to identify, track with the help of a receiver and a transmitter that is attached to the object. The RFID tags will be attached on books and the student or the staff will be issued an RFID card similar to that of their ID card. These cards and tags will be scanned using an RFID scanner/reader. The books will be then, issued when the user tag and the book tag is read and tagged. The books can be tracked and the other essential data like the existing and issued books can be kept in records.
\end{abstract}

\section{General Terms}

Library management system, RFID, RFID book tags and user cards, Inventory, Check in and out, Management.

\section{Keywords}

RFID, Library management system, RFID Library, RFID Library system, RFID book tags and user cards

\section{INTRODUCTION}

\subsection{Existing System}

Traditional libraries are currently using the barcoding technology which uses barcodes for identification of books and its information. The barcodes are scanned manually using barcode scanners by the librarian which involves much of human effort. The in-shelf books data is recorded by manually going and writing the name of the book and the serial numbers of the barcode. This process gives a tedious work to the librarian and its time consuming. This system also has a threat to books, as security is low and can be stolen easily from the library. The readers who take books must wait for a long time as the books and their cards must be scanned, tagged, and issued by the librarian which consumes more time.

\subsection{Proposed System}

The RFID book tags, and user cards serves as a solution to many problems. The RFID tags and cards contain radio frequency circuits that can be identified by the reader. They are identified using a transmitter and a receiver. These tags and user cards have a default serial number which can be customized as per need. The tags are pasted on the books. The serial number of the tag is paired with the book data in the existing database. The serial number of the user card is paired with the user details in the existing user database. This process is called tagging ${ }^{[1][8]}$.

\section{Components needed}

1. High Frequency RFID book tags $(13.56 \mathrm{MHz})$ ISO standard - ICODE - iso 15693

2. High Frequency RFID User cards $(13.56 \mathrm{MHz})$ ISO standard - MIFARE - iso 14443A

3. High Frequency RFID reader

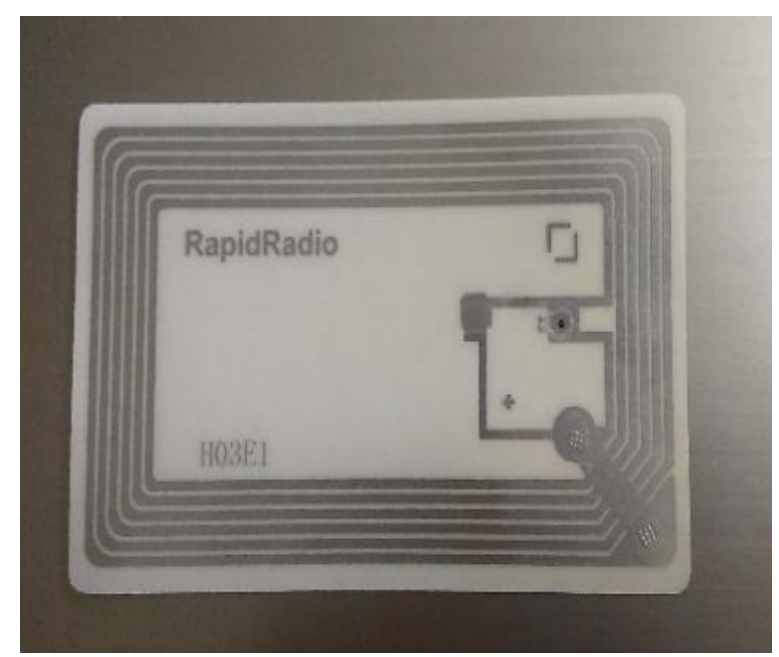

Fig 1: RFID Book-tag

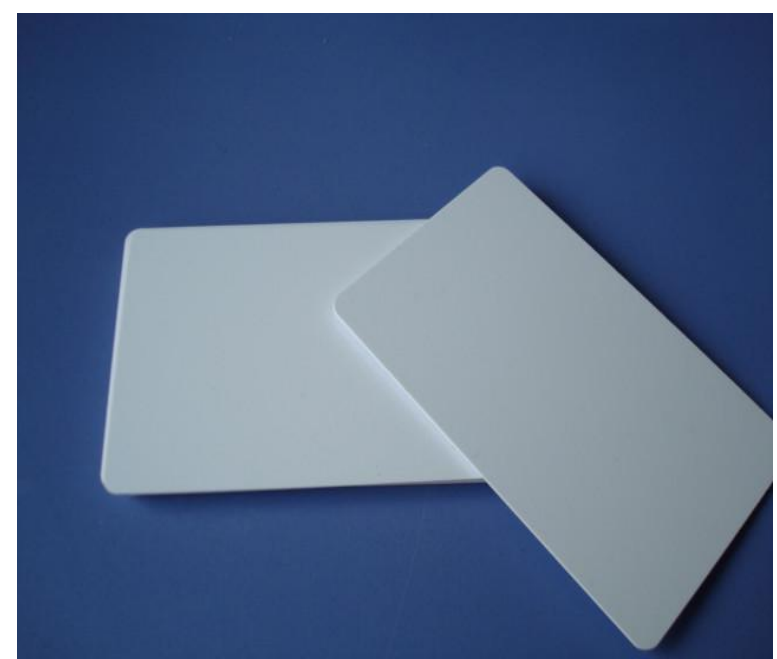

Fig 2: RFID User cards

\section{WORKING}

\subsection{Check-In and Check-Out}

The users check in and out using the RFID card and RFID reader. The scanned cards update the in and out count and the information of the user along with monitoring the 
attendance ${ }^{[4]}$. The users must scan their cards while coming in and must scan the cards while going out.

\subsection{Book Inventory}

The information of books that on the shelf can be recorded using a handheld RFID reader that is connected to the network and the existing database ${ }^{[9]}$. This reader can be used to capture the serial numbers of the RFID tags of the books that are in the shelves and update the issued and in-shelf records in the existing database.

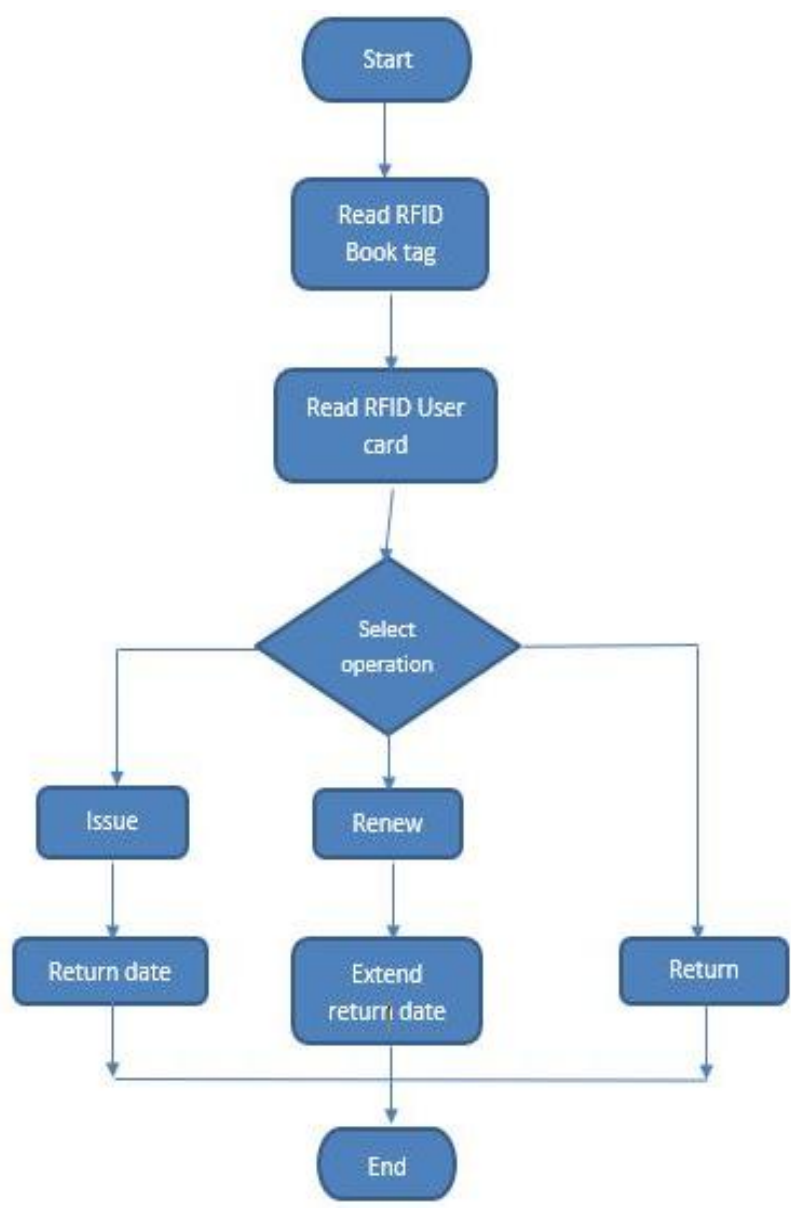

Fig 3: Dataflow diagram

\subsection{Issuing of books}

The RFID tags are scanned by the HF RFID reader when it is placed over the reader. The book tag and the user card are tagged by the librarian and issued. This process can also be done by the user themselves which consumes less time. This process of self-issuing books can be done separately[8].

The RFID reader serves as an input device and is connected to the system using a USB cable. Once the reader scans thee tag, the data of the user and the book is automatically fed and is tagged manually[3]. The issuing of the book can be done using open source library software (like KOHA, Librarian) or proprietary software (online/offline).

\subsection{Return/ Renewal of books}

The books must be returned/ renewed by the user after a period of days as per the policy of the library. The return date of the books which are pre-scheduled is again sent as a reminder via SMS notification. This process can be customized in the software. The returning/ renewing of the book is done by scanning both the tag of the book and the user card. Then, the librarian clicks on the action to be done (i.e., renew or return). This can also be done by the users themselves separately in the returning section.

\subsection{Anti-theft}

Book security can be achieved by placing RFID gates in the entry and exit points. These RFID gates detect the unscanned RFID tags that have not been tagged to any user card or removed from the in-shelf books database. This alerts the security system of the premises and the librarian that the book is being stolen along with the information of the user card and book tag that has been scanned simultaneously with the book that is not recorded in the issued database[2][10]. This measure ensures the book's safety.

\section{ADVANTAGES}

- Less time consumption

- Less manual work involved

- $\quad$ Easy book issuing and record updating

- Self-book issuing/tagging Read multiple tags simultaneously

\subsection{Challenges overcome: \\ - Anti-theft (book security) \\ - Maintenance of inventory}

\section{CONCLUSION}

Based on the theoretical study and analysis, we can conclude that, the RFID based library management will serve as a suitable alternative to the existing system of using barcodes for library books. The proposed system ensures proper books inventory management, books safety, record maintenance for issued and in-stock books, easy and self-book issuing, renewal and return of books. This system also ensures that it reduces the time taken in the overall processes like tagging, issuing, etc. for both the students and the librarian.

\section{FUTURE WORK}

The future work includes installation of wide range scanners for tracking of each books to ensure better security, installation of wide RFID sensor gates at entrances and exits for better and effective scanning of multiple user cards simultaneously.

\section{ACKNOWLEDGMENTS}

Our thanks to the Department of Computer Science and Engineering, SCSVMV (Deemed to bee University), Kanchipuram for providing us with all the support and to our families for constant encouragement.

\section{REFERENCES}

[1]. Library Management System Using RFID Technology, Sree Lakshmi Addepalli et al, / (IJCSIT) International Journal of Computer Science and Information Technologies, Vol. 5 (6), 2014, 6932-6935

[2]. Challenges, Drawbacks and Best Practices of RFID Technology in Handling of Information and Libraries, Kaginelli Pampapati ${ }^{1}$ and Dr.Dhanamjaya ${ }^{2}$, International Journal of Research in Management \& Social Science Volume 2, Issue 2 (III)

[3]. RFID Based Library Management System: The Benefits and Challenges, Diljeetkaur G. Makhija1 and Pawan K. Chugan2 
[4]. RFID Based Library Management System, Amit, JETIR (ISSN-2349-5162) June 2017, Volume 4, Issue 6

[5]. Recent Trends in Library Management System: RFID Technology, Sheikh Mohd Imran ${ }^{1}$ Nisar Ahmad Dar ${ }^{2}$ Muzamil Mushtaq ${ }^{3}$,

[6]. An RFID-Based Library Management System Using Smart Cabinets: A Pilot Project, Anastasis C. Polycarpou ${ }^{1}$, Theodoros Samaras2, and John N. Sahalos ${ }^{1,2}$, The 8th European Conference on Antennas and Propagation (EuCAP 2014)

[7]. RFID Based Library Management System, SVimalraj* S.Sameera S.Saranya, International Journal of Innovative
Research in Advanced Engineering (IJIRAE) ISSN: 2349-2163 Issue 1, Volume 2 (January 2015)

[8]. RFID Based Library Management System Dhanalakshmi M, Uppala Mamatha

[9]. RFID Library Implementation, Akansha Verma ${ }^{1}$, Niharika Garg ${ }^{2}$, IJCSMC, Vol. 3, Issue. 4, April 2014

[10].Smart Library Management System Using RFID Technology, Chetan J. Jadhav ${ }^{1}$, Shivani S. Jadhav ${ }^{2}$, Vijay M. Sacheti ${ }^{3}$, Prof. Shailesh S. Hajare ${ }^{4}$, International Research Journal of Engineering and Technology (IRJET), Volume: 04 Issue: 05 (May -2017) 